\title{
TEXTOGRAPHY AS A STRATEGY FOR INVESTIGATION: WRITING IN HIGHER EDUCATION AND IN THE PROFESSIONS
}

\author{
BRIAN PALTRIDGE AND MARIE STEVENSON
}

\section{ABSTRAC T}

This paper presents textography as a research strategy in writing research that enables texts and their surrounding contexts, practices and the relationships between these to be examined in detail. In order to illustrate the potential of textography, the paper explores how textography could be used to examine the relationships between writing in higher education and writing in the workplace. The paper argues that the time is ripe for the investigation of study-workplace connections for writing in plurilingual settings, such as in Nordic contexts.

\section{[1] TEXTOGRAPHy AS A STRATEgy FOR INVESTIGATION}

Research into writing is traditionally either textual or contextual in orientation. There is a rich body of text analytic research that has examined the genres, and related rhetorical and textual features of texts, in particular in academic texts (see Shaw, 2016 for a review of this work). There is also a strong tradition of research carried out within an academic literacies perspective (see Lillis \& Tuck, 2016) that focuses on the contexts in which writing takes place through ethnographic techniques such as interviews and observations, and which has provided rich insights into the lived experiences of writers, the practices in which they engage, the contexts in which these practices are located, and how these contexts shape literacy practices. In many cases, however, these two strands of research remain largely separated (Lillis \& Curry, 2015).

A research strategy that enables the researcher to combine a textual with a contextual orientation is what Swales (1998a; Swales \& Luebs, 1995) has termed textography. This strategy goes beyond the text (Freedman, 1999) in its examination of both texts and contexts, and the relationships between them. Textography, in sum, combines elements of discourse analysis with ethnographic techniques such as interviews, observations, and document analysis. It is, thus, something more than a traditional piece of discourse analysis, while at the 
same time less than a full-blown ethnography. A textography aims to get an inside view of the worlds in which texts are written, why texts are written as they are, what guides the writing, and the values that underlie the texts that have been written (Katz, 1999). A particular goal of a textography is to examine the contextualization and the situatedness of written texts (Swales, 1998a). It aims to do this through an exploration of the texts' 'contextually embedded discursive practices' (Swales, 1998a, p. 112). A textography, thus, aims to provide a 'thick description' (Geertz, 1973) of the context in which texts are produced in order to gain an understanding of why the texts are written as they are.

In his book Other Floors, Other Voices, Swales (1998b) carried out a textography of the kinds of writing that people who worked on three different floors of his building at the University of Michigan were engaged in and the kinds of texts that they wrote. He looked at their texts as well as gathering observation data, carrying out document and correspondence analysis, and conducting text-based interviews with employees on each floor of the building. From this material, textual life histories were put together of seven of the people who worked in the building, including Swales himself. Swales found that people on each floor of his building wrote quite different texts, even though they were all working at the same institution. He also found the writers' professional and academic histories and their life commitments had an important influence on what they wrote and how they wrote it.

A further study which employed textography was a project that examined the exegeses that art and design students write in their master's degrees (Paltridge, 2004). An exegesis is a written text that accompanies a visual project submitted as the research component of the student's degree. These texts are similar in some ways to what is called the thesis genre, but in many ways are also quite different. An analysis of the exegeses themselves was combined with an examination of texts that surrounded the exegeses, such as the postgraduate student handbook, the guide to examiners, examiners' reports, and the annual report on the master's degree. Interviews were also carried out with students, advisors, and examiners of the exegeses. This was done in order to explore the particular nature and character of the students' texts, the values that underlay the texts, and the role the texts played in the particular academic setting; that is, to examine the texts, role and context of the students' texts (Johns, 1997).

Paltridge et al (Paltridge et al., 2012a, 2012b; Ravelli et al., 2013; Starfield et al., 2012) also employed textography in their study of texts that visual and performing arts doctoral students write as part of the submission requirements for their doctoral degrees. Data collected for their study included a nation-wide 
survey, 36 dissertations, 36 supervisor questionnaires, 15 student interviews, 15 supervisor interviews, university prospectuses, information given to students in relation to their candidature, published research on doctoral research and examination in these areas of study, in-house art school publications, discussion papers, and attendance at roundtable discussions and exhibition openings. The study found that there were a range of ways in which students could write their texts as well as reasons for this range, some of which were institutional, and some of which were due to the influence of key figures in the field, rather than conventions of the particular disciplines.

Textographies, thus, provide insights into the production and interpretation of texts that would not be gained if texts or contexts on their own were examined. They are able to show diversities of practices across fields of study and across domains, providing understandings for why this might be the case. More broadly, textographies support the case made for the importance of contextualizing academic writing by researchers such as Lillis, (2008), Paltridge, Starfield and Tardy (2016), Perales-Escudero and Swales (2011) and Swales and Rogers (1995).

The use of textographies, then, we would argue, provides writing researchers with a way of looking at writing where the whole "can equal more than the sum of the parts' (Flowerdew, 2011, p. 119). In the following sections, we take writing in higher education and the professions as an example to illustrate in more detail how textography could be applied.

\section{[2] WRITING IN Higher EDUCATION AND THE PROFESSIONS}

Participation rates in higher education are growing rapidly in many countries around the world (Marginson, 2016), with consequent growing diversity in student populations. These changes are accompanied by evolving notions of what university education is and shifts in the relationships between universities and workplaces (Boden \& Nedeva, 2010). From traditional views that universities are about pure learning and the acquisition of social and cultural capital (Chan, 2016), increasingly a major role of universities is seen to be the provision of graduates possessing specific knowledge and skills that meet both the employment needs of graduates themselves and the organizations in which they seek to gain employment.

Consequently, universities and workplaces increasingly share a discourse of 'employability'. In the European context, the Bologna process has placed great emphasis on improving employability of university graduates (The Bologna Declaration, 1999), the aim being to produce a flexible, innovative and plurilingual workforce. In English-speaking countries, 'graduate attributes', which are 
inventories of qualities that graduates are expected to possess as formulated by universities, are currently tied to the notion of employability (Tempone et al, 2012), with growing expectations that learning outcomes in specific subjects of study are explicitly linked to these graduate attributes. While some hail these developments as increasing the social relevance of higher education and the social and economic participation of the growing number of graduates, the discourses surrounding employability have also been critiqued as being symptomatic of a neoliberal commodification of higher education (Boden \& Nedeva, 2010; Noonan, \& Mireille, 2015). Whatever one's stance, these developments signal a need to investigate connections between higher education and the workplace more closely.

Effective written communication is a quality that is highly valued in both educational and workplace settings (see Tempone et al, 2012), and studyworkplace connections have already been the subject of some research. Research has shown that writing in academic and professional settings, however, is often 'worlds apart'. In a book with this title, Dias et al (1999) identified large differences in the genres that writers produce in educational and workplace contexts and in the practices in which they engage. They compared written genres and practices in related university and workplace settings in Canada. They found that, in the workplace, action-oriented genres with a social purpose were common, whereas in academic settings the texts produced by students generally only had the epistemic purpose of displaying knowledge and skills for assessment. They also found that in the workplace, in contrast with academic settings, practices such as document recycling, collaborative writing, and copying from other workplace texts without acknowledging sources were common, and that texts were likely to be read by multiple readers for different purposes. In a study of the changing writing demands from the last year of university study to the first year in the workforce of engineering and accounting professionals in Australia, Knoch et al. (2016) found that employers reported graduates as being poorly prepared for the workplace in terms of their familiarity with workplace genres.

Both Dias et al. (1999) and Knoch et al. (2016) have called for the gap between university and workplace writing to be bridged. An obvious way of bridging the gap suggested in the literature is to expose students to real or simulated situations from the workplace to encourage the production of more 'authentic' writing, that is, writing that matches more closely to workplace writing. For example, in an investigation of the perceptions of Canadian university students, Schneider \& Andre (2005) found that students from disciplines that had received practice in workplace genres were more satisfied with their prepared- 
ness than those from disciplines who had not. However, while scholars have recommended the teaching of workplace genres in higher educational settings or have reported that this has been done, there is little research on exactly how this has been done, or how this can be done effectively.

However, what the literature has identified are difficulties related to teaching workplace genres in higher educational settings. Candy and Crebert (1991) made the point that workplaces are so diverse that it may not be feasible to prepare students in terms of their specific genres. Moreover, it has been argued that the differences in contexts of production in universities and workplaces may preclude the effective simulation of workplace genres. Dias et al (1999) concluded that 'school-based simulations of workplace writing fail to prepare students for professional writing because they cannot adequately replicate the local rhetorical complexity of workplace contexts' (p. 201). Spinuzzi (1996) pointed to the 'pseudo-transactionality' of academic writing as a significant impediment to bridging the gap between higher education and the workplace. Spinuzzi gave his students an authentic letter writing task, with the resulting letters being sent to companies, but found that despite the seeming authenticity of the task, students' awareness of the assessable nature of the writing tasks affected both content and form, leading to texts that nonetheless appeared to be primarily written to meet the teacher's expectations rather than to fulfill a social purpose beyond assessing students' writing.

Hence, it has been suggested that, rather than trying to replicate the genres or contexts of production of workplace texts, a more appropriate means of bridging the gap between study and the workplace is for higher education to focus on raising students' awareness of differences in social purposes and audiences for a variety of genres, and on developing students' flexibility in adapting to these (e.g. Knoch et al, 2016; Artemeva, 2008). According to Candy and Crebert (1991), employers express a desire for universities to provide them with graduates who have generic communication skills, and are flexible: they do not necessarily expect graduates to be familiar with specific workplace genres. Employers may expect that new graduates will demonstrate the ability to develop specific skills quickly and be able to apply them to new and unfamiliar situations, rather than expecting them to arrive in the workplace having already mastered specific genres. However, to date, little evidence exists concerning how writing in the disciplines could - or does - explicitly raise genre awareness, and whether this awareness could be applied in workplace writing.

Another aspect of this complex issue is that it may be English language use, rather than either lack of familiarity with specific workplace genres or lack of more general genre awareness, which forms the major barrier to effective writ- 
ten communication in the workplace. In recent years, many complaints have been made in the popular press - in English-speaking countries at least - about the poor literacy levels of graduates, and studies carried out in Englishspeaking countries have found that employers perceive graduates to have poor written communication skills (e.g. Grebbennikov \& Shah, 2008; Haberstroh, 1994/1995). Many of these complaints appear to be about matters of usage such as grammar, style and tone rather than higher level concerns, such as genre knowledge or audience awareness. Some of the blame for poor language use has been laid at the door of universities. Knoch et al (2016) found that university lecturers appeared to have different criteria for evaluating texts than employers, placing considerably more emphasis on content than correctness of language use. The quality of language use was often not included in their assessment criteria, or received only minimal attention. In contrast, in the workplace, while content was also important, employers placed much emphasis on writing that was grammatically correct and appropriate to the audience in terms of tone and style. Employers have expressed the view that universities devote insufficient attention to writing instruction (Kotzee \& Johnston, 2011), but it remains unclear to what extent this is feasible. Also, little is known about the characteristics of texts that educators and employers consider to be successful or unsuccessful. In particular, little is known about graduates' written communication skills in plurilingual study and work contexts, such as are common in Nordic countries. It could be that in such plurilingual environments accuracy of language use plays a different or lesser role than in settings in English-speaking countries in which English is the only medium of communication.

A fourth and final issue is the extent to which the onus should actually be on universities to prepare students for workplace writing, or whether workplaces need to accept that the major responsibility lies with them. Little research has examined the nature of on-the-job guidance in writing that graduates receive in the workplace. Jackson (2000) has critiqued the discourse of deficit surrounding graduates' writing in the workplace, saying that it is changes in the relations of literacy in the workplace, rather than workers' literacy, that is the issue: in the current culture of accountability the written words of workers become 'data' (p. 263) in the managerial process. Parkes (Parkes \& Maguire, 1999; Parkes, 2001) illustrates a case in which novice graduate nurses push back, resisting attempts of their employers to force them to conform to a standard genre that they were taught to write during their vocational studies. Under the influence of more experienced nursing peers, the novice nurses in Canada became increasingly resistant to writing care plans in the standard manner they had been taught at university, even though the hospital wanted them to con- 
tinue doing this. This showed that complex social dynamics in the workplace may lead to shifts in workplace genres so that they no longer align with standard genres taught during vocation training.

\section{[3] TEXTOGRAPHY FOR STUDY-WORK RELATIONSHIPS}

The above discussion has highlighted some of the complexities of comparing writing in higher education and the professions. To date, only a small amount of the existing research has actually been situated in both higher education and the workplace (i.e., Dias et al, 1999; Knoch et al, 2016). Much of the other research is situated in the workplace only and looks at how novice professionals who have just graduated negotiate the kinds of writing required in their professions, or at how employers view new graduates in terms of their preparedness for professional writing. Thus, there is a need for further research that investigates writing in both of these settings. We argue, thus, that textography provides a valuable research strategy for undertaking this investigation.

Existing research on study-workplace connections has been strong in investigating the contexts in which writing takes place. For example, the Knoch et al (2016) study examined the perceptions of stakeholders (lecturers and professionals) in study and workplace contexts and interviewed students. The Dias et al (1999) study provided insights into genre differences that relate to differences in the context of the academic and workplace writing. While their study provided some textual analysis, it did not directly compare university and workplace texts. In fact, little is known about the characteristics of texts that are considered to be successful or unsuccessful in workplace settings, or whether academic writing in higher education focuses on these characteristics. In particular, more insight is needed into whether higher level aspects of writing such as genre knowledge and audience awareness (Tardy, 2009) are perceived as lacking or whether it is lower level linguistic aspects, such as grammar and vocabulary. A textographic approach enables in-depth textual analyses that can address these issues.

Research to date, further, has provided valuable insights into differences between academic and workplace writing, but has focussed little on the extent to which the development of writing is supported in higher educational and workplace contexts. Little is known about which approaches to practising the kind of writing needed in the workplace, such as teaching workplace genres in higher education or raising general genre awareness, are being applied or how these are being applied. Similarly, in workplace settings, little is known about on-the-job training or mentoring in developing effective written communication. A textographic approach enables ongoing engagement with the actual 
sites of writing, including observation of both the teaching and learning of writing in these sites.

In addition, the majority of research in this area has, to date, been carried out in English-speaking contexts in which English appears to be the only medium of communication. The diversity of writers - multilingual writers of different language backgrounds - and the diversity of settings, such as international workplace settings where English functions as a lingua franca, have largely been ignored. More recognition is needed of the multilingual nature of writing and writers, as well as the influence of the socio-cultural contexts in shaping the writing that takes place. Specifically, there is a need for textographic research to be carried out in plurilingual settings in which more than one language is used in the workplace, such as in Nordic contexts. Compared to higher educational contexts in English-speaking countries, Nordic higher educational contexts are typified by relatively high levels of social equality, relatively homogeneous student populations - although this situation is changing rapidly and a stronger differentiation between vocational education and university education. In addition, graduates are expected to possess high levels of literacy in both English and the national language(s), which in the case of Finland, for example, means literacy in both Finnish and Swedish (Lehtonen \& Karjalainen, 2008). In Nordic countries, plurilingual workplaces are increasingly common, which makes Nordic contexts interesting for the examination of studyworkplace connections between writing in a plurlingual setting.

The kinds of questions that textographic research could answer are:

- What are stakeholders' in the disciplines and the professions perceptions and roles concerning students' writing and their own roles in developing students' workplace writing?

- How are writers being prepared for workplace writing both in the disciplines and the professions?

- What are the characteristics of successful and unsuccessful writing in the disciplines and the professions?

- How do writers of diverse backgrounds negotiate the demands of writing in English in the professions, particularly in plurilingual settings?

A textographic approach to answering questions such as the above could commence with a large-scale survey conducted in a range of disciplinary and 
workplace settings in order to establish stakeholders' perceptions of writing needs and their role in supporting writing. This survey could be used to select a smaller number of case study sites in parallel disciplinary and professional settings.

The case studies would involve the collection and examination of texts, as well as the use of research strategies that aim to gain insiders' views of writing practices, writers' experiences, and the contexts in which the writing is produced and evaluated in the different disciplinary and professional contexts. Data collected would include examples of texts written in each of the parallel settings, as well as interview and observation data in order to gain insights into how the texts are written and why. Other data could include advice given to writers on their texts and any explicit instruction, written guidelines or feedback that are available to assist them in the production of their texts. Following on from the work of Paltridge $(2004,2017)$, analysis could include a focus on both the immediate and broader socio-cultural contexts in which the texts are produced and how this impacts on what people write in each of the settings. In terms of what writers need to understand to write successful texts, writers and stakeholders could be interviewed to establish what formal knowledge, process knowledge, rhetorical knowledge and content knowledge (Tardy, 2009) they see as being essential to the writing of texts in their contexts.

\section{[4] CONCLUSION}

The value of a textographic research strategy, then, is the understanding that it provides of what kinds of writing professionals undertake as part of their duties, how their writing is produced, and what is valued in that writing. This can then be compared with the kinds of writing that are required in the parallel disciplinary area in higher education settings, as well as considering whether and how this writing might be changed so as to better prepare students for the kinds of writing writers do in the professions.

Answering questions such as those formulated above, we argue, will provide evidence that can inform us about the degree to which there is, can be, or should be alignment between academic and workplace writing in specific settings, and, if appropriate, which strategies can be implemented to increase this alignment and thus ease the transition from higher education to the workplace. The proposal we make, thus, aims, through the insights that will be gained, to provide a research-informed basis for working towards making this transition more successful for students as they move from higher education to professional settings.

As long ago as 1985, Swales argued that: 
It is not only texts that we need to understand, but the roles texts have in their environments; the values, congruent and conflictive, placed on them by occupational, professional and disciplinary memberships; and the expectations those memberships have of the patternings of the genres they participate in.

(Swales, 1985, p. 219)

This paper has illustrated how textography can be applied to achieve this. Textography can assist in 'closing the gap between text and context' (Lillis, 2008 , p. 353) by combining textual and contextual approaches to the analysis of writing, in order to give insights that might not be gained by relying on just one of these approaches alone (Starfield, Paltridge \& Ravelli, 2014).

\section{BIBLIOGRAPHY}

Artemeva, Natasha. 2008. Towards a unified social theory of genre learning. Journal of Business and Technical Communication, 22(2). 160-185.

Boden, Rebecca \& Maria Nedeva. 2010. Employing discourse: Universities and graduate 'employability'. Journal of Educational Policy, 25(1). 37-54.

Candy, Phillip C. \& R. G. Crebert. 1991. Ivory tower to concrete jungle: The difficult transition from the academy to the workplace as learning environments. Journal of Higher Education, 62(5). 568-592.

Chan, Roy Y. 2016. Understanding the purpose of higher education: An analysis of the economic and social benefits for completing a college degree. Journal of Education Policy, Planning, and Administration (JEPPA), 6(5). 1-40.

Dias, Patrick, Aviva Freedman, Peter Medway \& Antony Paré. 1999. Worlds Apart: Acting and Writing in Academic and Workplace Contexts. Mahwah, NJ: Lawrence Erlbaum.

Flowerdew, John. 2011. Reconciling contrasting approaches to genre analysis: The whole can equal more than the sum of the parts. In Diane Belcher, Ann M. Johns \& Brian Paltridge (eds.), New Directions in English for Specific Purposes Research, 119-144. Ann Arbor: University of Michigan Press.

Freedman, Aviva. 1999. Beyond the text: Towards understanding the teaching and learning of genres. TESOL Quarterly, 33(4). 764-768.

Geertz, Clifford. 1973. The Interpretation of Culture. New York: Basic Books. 
Grebbennikov, Leonid \& Mahsood Shah. 2008. Engaging employers with the university: Skills needed and changes expected by industries. Presentation at Australian Universities Community Engagement Alliance Conference. Available at:

http://www.uws.edu.au/__data/assets/pdf_file/0014/121316/Engaging_em ployers_with_the_university_AUCEA08.pdf

Haberstroh, Jack. 1994/1995. PR graduates don't measure up as writers: What the pros think and what you can do about it. Public Relations Quarterly, 39(4). $22-24$.

Jackson, Nancy. 2000. Writing-up people at work: Investigations of workplace literacy. In Colin Symes (ed.), Working Knowledge: Productive Learning at Work, 263-272. Sydney: Proceedings (of the) International Conference.

Johns, Ann M. 1997. Text, Role and Context: Developing Academic Literacies. Cambridge: Cambridge University Press.

Katz, Susan M. 1999. Other floors, other voices: A textography of a small university building. The Journal of Business Communication, 36(4). 422.

Kotzee, Ben \& Roger Johnston. 2011. 'Can't string a sentence together'? UK employers' views of graduate writing skills. Industry and Higher Education, 25(1). 45-52.

Knoch, Ute, Lynn May, Susi Macqueen, John Pill \& Neomy Storch, 2016. Transitioning from university to the workplace: Stakeholder perceptions of academic and professional writing demands. IELTS Research Report Series, 1. 137.

Lehtonen, Tuula \& Sinikka Karjalainen. 2008. University graduates' workplace language needs as perceived by employers. System, 36(3). 492-503.

Lillis, Theresa M. 2008. Ethnography as method, methodology, and "deep theorizing". Written Communication, 25(3). 353-388.

Lillis, Theresa M. \& Mary Jane Curry. 2015. The politics of English, language and uptake. The case of international academic journal article reviews. AILA Review, 28. 127-150.

Lillis, Theresa M. \& Jackie Tuck. 2016. Academic literacies: A critical lens on writing and reading in the academy. In Ken Hyland \& Phillip Shaw (eds.), The Routledge Handbook of English for Academic Purposes, 30-43. London: Routledge. 
Marginson, Simon. 2016. The worldwide trend to high participation higher education: dynamics of social stratification in inclusive systems. Higher Education, 72(4). 413-434.

Noonan, Jeff \& Mireille Coral. 2015. The tyranny of work: Employability and the neoliberal assault on education. Alternate Routes, 26. 51-73.

Paltridge, Brian 2004. The exegesis as a genre: An ethnographic examination. In Louise Ravelli \& Rob Ellis (eds.), Analyzing Academic Writing: Contextualised Frameworks, 84-103. London: Continuum.

Paltridge, Brian. 2017. Context and the teaching of academic writing: Bringing together theory and practice. In John Bitchener, Neomy Storch \& Rosemary Wette (eds.), Teaching Writing for Academic Purposes to Multilingual Students, 923. New York: Routledge.

Paltridge, Brian, Sue Starfield, Louise Ravelli \& Kathryn Tuckwell. 2012a. Change and stability: Examining the macrostructures of doctoral theses in the visual and performing arts. Journal of English for Academic Purposes, 11(4). 332-334.

Paltridge, Brian, Sue Starfield, Louise Ravelli, Sarah Nicholson \& Kathryn Tuckwell. 2012b. Doctoral writing in the visual and performing arts: Two ends of a continuum. Studies in Higher Education, 37(8). 989-1003.

Paltridge, Brian., Sue Starfield \& Christine. M. Tardy. 2016. Ethnographic Perspectives on Academic Writing. Oxford: Oxford University Press.

Parkes, Susan. 1991. Moving from school to the workplace: Disciplinary innovation, border crossings, and the reshaping of a written genre. Applied Linguistics, 22(4). 405-438.

Parkes, Susan \& Mary. H. Maguire. 1999. Coping with on-the-job writing in ESL: A constructivist-semiotic perspective. Language Learning, 49(1). 143-175.

Perales-Escudero, Moisés \& John M. Swales. 2011. Tracing convergence and divergence in pairs of Spanish and English research article abstracts: The case of Ibérica. Ibercia, 21. 49-70.

Ravelli, Louise, Brian Paltridge, Sue Starfield \& Kathyrn Tuckwell. 2013. Extending the notion of text: The creative arts doctoral thesis. Visual Communication, 12(4). 395-422.

Schneider, Barbara \& Jo-Anne Andre. 2005. University preparation of work- 
place writing: An exploratory study of the perceptions of students in three disciplines. International Journal of Business Communication, 42(2). 195-218.

Shaw, Phillip. 2016. Genre analysis. In K. Hyland \& P. Shaw (eds.), The Routledge Handbook of English for Academic Purposes, 243- 255. London: Routledge.

Starfield, Sue, Brian Paltridge \& Louise Ravelli. 2012. "Why do we have to write?" Practice-based theses in the visual and performing arts and the place of writing. In Vijay Bhatia \& Carol Berkenkotter (eds.), Insights into Academic Genres, 169-190. Bern: Peter Lang.

Spinuzzi, Clay. 1996. Pseudotransactionality, activity theory, and professional writing instruction. Technical Communication Quarterly, 5(3). 295-308.

Starfield, Sue, Brian Paltridge \& Louise Ravelli. 2014. Researching academic writing: What textography affords. In John Huisman \& Malcolm Tight (eds.), Theory and Method in Higher Education Research II, 103-120. Oxford: Emerald.

Swales, John M. 1985. ESP - the heart of the matter or the end of the affair? In Randolf Quirk \& Henry G. Widdowson (eds.), English in the World , 212-223. Cambridge: Cambridge University Press.

Swales, John M. 1998a. Textography: Toward a contextualization of written academic discourse. Research on Language and Social Interaction, 31(1). 109-121.

Swales, John M. 1998b. Other Floors, Other Voices: A Textography of a Small University Building. Mahwah, NJ: Laurence Erlbaum.

Swales, John M. \& Margaret Luebs. 1995. Towards textography. In Britt-Louise Gunnarsson \& Ingegerd Backlund (eds.), Writing in Academic Contexts, 12-29. Uppsala: FUMS.

Swales, John M. \& Priscilla Rogers. 1995. Discourse and the projection of corporate culture: The mission statement. Discourse and Society, 6(2). 223-242.

Tardy, Christine. M. 2009. Building Genre knowledge. West Lafayette, IN: Parlor Press.

Tempone, Irene, Marie Kavanagh, Naomi Segal, Phil Hancock, Bryan Howieson \& Jenny Kent. 2012. Desirable generic attributes for accounting graduates into the twenty-first century: The views of employers. Accounting Research Journal, 25(1). 41-55.

The Bologna Declaration. 1999. The Bologna Declaration of 19 June 1999. Joint 
declaration of the European ministers of education. http://www.bolognabergen2005.no/Docs/00-Main_doc/990719BOLOGNA_DECLARATION.PDF

CONTACTS

Brian Paltridge

University of Sydney

brian.paltridge@sydney.edu.au

Marie Stevenson

University of Sydney

marie.stevenson@sydney.edu.au 